\title{
Exchange rate pass-through, exchange rate volatility, and exchange rate disconnect ${ }^{2}$
}

\author{
Michael B. Devereux ${ }^{\mathrm{a}, \mathrm{b}}$, Charles Engel ${ }^{\mathrm{c}, \mathrm{d}, *}$ \\ ${ }^{a}$ Department of Economics, University of British Columbia, Vancouver, BC, Canada V6T 1Z1 \\ ${ }^{\mathrm{b}}$ Centre for Economic Policy Research, London ECIV 7RR, UK \\ ${ }^{\mathrm{c}}$ Department of Economics, University of Wisconsin, 1180 Observatory Drive, Madison, WI 53706-1393, \\ USA \\ ${ }^{\mathrm{d}}$ National Bureau of Economic Research, Cambridge, MA 02138, USA
}

Received 16 November 2001; received in revised form 5 February 2002; accepted 8 February 2002

\begin{abstract}
This paper explores the hypothesis that high volatility of real and nominal exchange rates may be due to the fact that local currency pricing eliminates the pass-through from changes in exchange rates to consumer prices. Exchange rates may be highly volatile because in a sense they have little effect on macroeconomic variables. The paper shows the ingredients necessary to construct such an explanation for exchange rate volatility. In addition to the presence of local currency pricing, we need (a) incomplete international financial markets, (b) a structure of international pricing and product distribution such that wealth effects of exchange rate changes are minimized, and (c) stochastic deviations from uncovered interest rate parity. Together, it is shown that these elements can produce exchange rate volatility that is much higher than shocks to economic fundamentals, and 'disconnected' from the rest of the economy in the sense that the volatility of all other macroeconomic aggregates are of the same order as that of fundamentals. (C) 2002 Elsevier Science B.V. All rights reserved.
\end{abstract}

JEL classification: $\mathrm{F} 3 ; \mathrm{F} 4$

Keywords: Exchange rate pass-through; Exchange rate volatility; Exchange rate disconnect; Local currency pricing; Noise traders

in This paper was prepared for the Carnegie-Rochester Conference, Carnegie Mellon University, November 16-17, 2001. We thank Margarida Duarte and Bennett McCallum for helpful comments. Devereux thanks SSHRC for financial assistance. Engel thanks the NSF for funding.

*Corresponding author. Department of Economics, University of Wisconsin, 1180 Observatory Drive, Madison, WI 53706-1393, USA. Tel.: + 1-608-262-3697; fax: + 1-608-263-3876.

E-mail addresses: devm@interchange.ubc.ca (M.B. Devereux), cengel@ssc.wisc.edu (C. Engel). 
Empirical evidence indicates that nominal exchange rate changes are not fully passed through to goods prices. In fact, it appears that consumer prices are very unresponsive to nominal exchange rate changes. ${ }^{1}$ An implication of this finding is that the "expenditure-switching" effect of exchange rate changes might be very small. That is, a change in the nominal exchange rate might not lead to much substitution between domestically produced goods and internationally produced goods, because the relative prices of those goods do not change much for final users.

If the exchange rate change has little effect on the behavior of final purchasers of goods, then it may take large changes in exchange rates to achieve equilibrium after some shock to fundamentals. For example, if there is a shock that reduces the supply of foreign goods, a very large home depreciation might be required in order to raise the relative price of foreign goods enough to reduce demand sufficiently. That is, low pass-through of exchange rates might imply high exchange rate volatility in equilibrium. That intuition was first expressed by Krugman (1989), and explored by Betts and Devereux (1996).

However, fully articulated equilibrium open-economy macroeconomic models with sticky nominal prices (in the style of Obstfeld and Rogoff (1995)) have found that exchange rate volatility is difficult to generate even when there is little exchange rate pass-through. While Obstfeld and Rogoff (1995) assume complete pass-through of exchange rates to prices because they assume that nominal prices are set in the currency of the producer, several studies have extended the Obstfeld-Rogoff framework to the local-currency pricing case. ${ }^{2}$ Under local-currency pricing, firms set a price in their own currency for sale to households located in their country, but set a price in foreign currency for sales to foreign households.

The purpose of this paper is to explore the conditions under which local-currency pricing might induce a high level of exchange rate volatility. By impeding the linkage of goods prices across countries, local currency pricing leads to deviations from purchasing power parity (PPP), and therefore, in principal, may be able to explain high exchange rate volatility following the intuition of Krugman. But there are some major caveats to this conclusion. Much of the paper is devoted to understanding them. First, if international financial markets allow for full risk-sharing across countries, then exchange rates will be determined by a risk sharing condition, despite the fact that local currency prices are independent of exchange rates. Second, even if risk sharing is limited, the linkage of assets prices through bond markets will impose a tight limit on the degree to which exchange rates can move. Third, even without any international asset trade at all, local currency pricing does not guarantee high exchange rate volatility because wealth effects of exchange rate changes through firms' profits will limit the degree to which the exchange rate can change. Finally, while within a particular model of local currency pricing it may be feasible to choose a parameter configuration that delivers a high level of exchange rate variability (e.g. Chari et al., 2000), this parameterization may have quite counterfactual implications for other macroeconomic variables. Our aim is not just to explain high exchange rate

\footnotetext{
${ }^{1}$ See Engel (1993), Parsley and Wei (2001), or the references cited therein.

${ }^{2}$ See Betts and Devereux (1996, 2000) and Devereux and Engel (2000).
} 
volatility, but, in the spirit of the original Krugman discussion, to understand both why exchange rate variability can both be high and not matter for real variables. In this respect, we are influenced by the seminal empirical findings of Baxter and Stockman (1989), Flood and Rose (1995). They show that high exchange rate volatility under floating exchange rates is not obviously tied to or reflected in high volatility of other macroeconomic variables. Exchange rates are a puzzle not just because they are volatile, but also because they seem to be 'disconnected' from the real economy, as discussed by Obstfeld and Rogoff (2000), and Duarte and Stockman (2001). ${ }^{3}$

Given these prerequisites for explaining exchange rate volatility, the paper constructs a model in which a combination of three factors is key in generating exchange rate volatility that is much higher than the volatility in underlying macroeconomic shocks, or the volatility in other endogenous macroeconomic variables. The first factor is the presence of local currency pricing: exchange rate changes do not pass through to goods prices in the short run.

The second feature is the presence of heterogeneity in the way that products are sold and prices are set in international commodity markets. We assume that some firms market their products directly in their export market, but others use foreign distributors. When an exporting firm uses a foreign distributor, it sets the price in its own currency. The distributor takes on the exchange rate risk-buying goods priced in the exporter's currency, and selling in the consumers' currency. In those cases, a home currency depreciation bestows a positive wealth shock on the distributor.

We posit that exporters are more likely to set up foreign offices and undertake their own distributing activities for large consumer markets, but they are more likely to sell to firms that specialize in distributing for sales to smaller markets. We show that under this configuration, the wealth effects of foreign exchange rate changes are minimized, potentially generating very high exchange rate volatility even for small shocks.

Finally, however, even with this structure of price setting and international commodity distribution, the degree of exchange rate volatility is restricted by arbitrage in international assets markets. When we allow for trade in non-contingent nominal bonds across countries, unanticipated movements in the exchange rate (in the presence of local currency pricing) generate a real interest rate differential across countries that itself tends to restrict the movement of the exchange rate. But this channel depends critically on the uncovered interest rate parity (UIRP) condition, which (aside from a negligible risk-premium term) continues to hold in a model of local currency pricing and heterogeneity in international goods distribution. In light of this, we extend our model to allow for the presence of foreign currency traders whose expectations of future exchange rates are conditionally biased. In this, we

\footnotetext{
${ }^{3}$ In many respects, our paper is similar to Duarte and Stockman (2001). They emphasize that shipping costs, leading to deviations from PPP, and volatile risk premiums, leading to deviation from UIRP, are joint requirements in the understanding of high exchange rate volatility. In our emphasis on the nature of international pricing and product distribution, as well as the nature of the breakdown in UIRP (see below), however, the channels explored in our paper are quite different.
} 
follow closely the recent paper of Jeanne and Rose (2002), showing how 'noisetraders' can generate high exchange rate volatility in a monetary model of the exchange rate.

Our results show that the presence of all three factors-local currency pricing, heterogeneous international distribution of commodities, and 'noise traders' in foreign exchange markets - can potentially generate a high-frequency volatility of the exchange rate that is completely out of proportion to the underlying monetary shocks to the economy. Moreover, while exchange rate volatility is ultimately tied to volatility in the fundamental shocks to the economy, the exchange rate can display extremely high volatility without any implications for the volatility of other macroeconomic variables. We find that the volatility of consumption, GDP, the real interest rate, and the current account may be quite low (of the same order of magnitude as fundamentals), while at the same time the volatility of the exchange rate may be much, much higher. In this sense, the exchange rate becomes 'disconnected' from the real economy.

The paper is organized as follows. In Section 1, we develop a baseline two-country general equilibrium model that is used throughout the paper. In that section we also show in detail why the assumption of complete international assets markets cannot provide an empirical explanation for exchange rate volatility. In Section 2, we illustrate the determination of the exchange rate under incomplete markets, local currency pricing, and heterogeneous international distribution in commodity markets. In order to develop the intuition, we restrict ourselves simply to a oneperiod horizon in that section, however. Section 3 extends the model to a dynamic (infinite horizon) environment, introducing a role for 'noise traders' in foreign exchange markets.

\section{The basic model of exchange rate determination}

Here we outline the basic features of the modeling framework. There are two countries; 'home' and 'foreign'. Households in each country maximize expected utility, which is a function of consumption, real balances and labor. They take prices and wages as given.

The representative household in the home country is assumed to maximize

$$
\mathrm{E}_{0} \sum_{t=0}^{\infty} \beta^{t} U\left(C_{t}, \frac{M_{t}}{P_{t}}, L_{t}\right), \quad \beta<1,
$$

where

$$
U=\frac{1}{1-\rho} C_{s}^{1-\rho}+\chi \ln \left(\frac{M_{s}}{P_{s}}\right)-\frac{\eta}{1+\psi} L_{s}^{1+\psi} \quad \text { and } \quad \rho>0 .
$$

Compared to other papers in the literature (Bacchetta and Van Wincoop, 2000; Chari et al., 2000), we make the assumption of separability in consumer preferences over consumption, real balances, and labor supply. In our model, the key features of exchange rate volatility will come from factors that are essentially independent of the 
preference specification. While allowing for non-separability on its own could alter some of our results (possibly generating a higher predicted level of exchange rate volatility for a given volatility of monetary policy for instance), it would not solve the 'exchange rate disconnect' problem.

$C$ is a consumption index that is a CES function of goods produced at home $\left(C_{\mathrm{h}}\right)$ and in the foreign country $\left(C_{\mathrm{f}}\right)$ :

$$
C=\left(n^{1 / \omega} C_{\mathrm{h}}^{1-1 / \omega}+(1-n)^{1 / \omega} C_{\mathrm{f}}^{1-1 / \omega}\right)^{\omega /(\omega-1)} .
$$

The elasticity of substitution between home and foreign consumption aggregates is $\omega$. We assume that there are $n$ identical households in the home country, $0<n<1 . C_{\mathrm{h}}$ and $C_{\mathrm{f}}$ are indexes:

$$
\begin{aligned}
& C_{\mathrm{h}}=\left[n^{-1 / \lambda} \int_{0}^{n} C_{\mathrm{h}}(i)^{\lambda-1 / \lambda} \mathrm{d} i\right]^{\lambda / \lambda-1}, \\
& C_{\mathrm{f}}=\left[(1-n)^{-1 / \lambda} \int_{n}^{1} C_{\mathrm{f}}(i)^{\lambda-1 / \lambda} \mathrm{d} i\right]^{\lambda / \lambda-1},
\end{aligned}
$$

where $\lambda>1 . M / P$ are domestic real balances, and $L$ is the labor supply of the representative home agent.

The price index, $P$, is defined by

$$
P=\left[n P_{\mathrm{h}}^{1-\omega}+(1-n) P_{\mathrm{f}}^{1-\omega}\right]^{1 / 1-\omega},
$$

where

$$
P_{\mathrm{h}}=\left[\frac{1}{n} \int_{0}^{n} P_{\mathrm{h}}(i)^{1-\lambda} \mathrm{d} i\right]^{1 / 1-\lambda}, \quad P_{\mathrm{f}}=\left[\frac{1}{1-n} \int_{n}^{1} P_{\mathrm{f}}(i)^{1-\lambda} \mathrm{d} i\right]^{1 / 1-\lambda} .
$$

There are $1-n$ identical households in the foreign country. Their preferences are similar to home country residents' preferences. The terms in the utility function involving consumption are identical in the home and foreign countries. The functional form for real balances and labor are the same as for the home country residents, but, for foreign residents, they are functions of foreign real balances and foreign labor supply. We denote foreign aggregate consumption by $C^{*}$ and the foreign price level by $P^{*}$. Throughout the paper an asterisk superscript indicates a foreign quantity.

Optimal consumption is given by

$$
\begin{aligned}
& C_{\mathrm{h}}(i)=\frac{1}{n}\left[\frac{P_{\mathrm{h}}(i)}{P_{\mathrm{h}}}\right]^{-\lambda} C_{\mathrm{h}}, \quad C_{\mathrm{f}}(i)=\frac{1}{1-n}\left[\frac{P_{\mathrm{f}}(i)}{P_{\mathrm{f}}}\right]^{-\lambda} C_{\mathrm{f}} \\
& C_{\mathrm{h}}=n\left[\frac{P_{\mathrm{h}}}{P}\right]^{-\omega} C, \quad C_{\mathrm{f}}=(1-n)\left[\frac{P_{\mathrm{f}}}{P}\right]^{-\omega} C \\
& \int_{0}^{n} P_{\mathrm{h}}(i) C_{\mathrm{h}}(i) \mathrm{d} i=P_{\mathrm{h}} C_{\mathrm{h}}, \quad \int_{n}^{1} P_{\mathrm{f}}(i) C_{\mathrm{f}}(i) \mathrm{d} i=P_{\mathrm{f}} C_{\mathrm{f}} .
\end{aligned}
$$




\subsection{Complete markets}

The choices available to households depend on the opportunities for financial market trade. The first result we obtain is a negative one. We will show that if there is a full set of state contingent nominal assets traded, then we cannot obtain high exchange rate volatility, or at least high volatility that is disconnected from the rest of the economy. When households of each country can purchase a full set of statecontingent nominal bonds, Chari et al. (2000) show that the following risk-sharing condition obtains

$$
\frac{S_{t} P_{t}^{*}}{P_{t}}=\Gamma_{0}\left(\frac{C_{t}}{C_{t}^{*}}\right)^{\rho},
$$

where $S_{t}$ is the home currency price of foreign currency, and $\Gamma_{0}$ is a constant, depending on initial conditions. ${ }^{4}$ Consumption will differ across the two countries only to the extent that there are changes in the real exchange rate.

In addition to the consumption demand equations listed above, we can derive the money demand equation for the representative home-country resident:

$$
\frac{M_{t}}{P_{t}}=\frac{\chi C_{t}^{\rho}}{\left(1-\mathrm{E}_{t} q_{t}\right)}
$$

where $q_{t}=\beta\left(P_{t} C_{t}^{\rho} / P_{t+1} C_{t+1}^{\rho}\right)$ is the equilibrium state contingent nominal pricing factor. The trade-off between consumption and leisure is given by

$$
W_{t}=\eta P_{t} C_{t}^{\rho} L_{t}^{\psi}
$$

Government increases the money supply with direct transfers. Home and foreign money transfers are determined as random injections, and these represent the only source of uncertainty in our model. We assume that the money supply follows a random walk:

$$
\mathrm{E}_{t}\left(\frac{M_{t}}{M_{t+1}}\right)=\mu, \quad \mu \leqslant 1 .
$$

The conditions for the foreign country are analogous. Using (1.2) and (1.4), it is easy to demonstrate that the nominal interest rate is time invariant, and equal to $(1 / \beta \mu)-1$. Then without any further specification of the model, we can derive an equilibrium expression for the exchange rate. Eqs. (1.1) and (1.2) yield

$$
S_{t}=\frac{M_{t}}{M_{t}^{*}}
$$

According to this relationship, the exchange rate is proportional to relative money supplies. That is, the exchange rate is no more volatile than the fundamentals.

The striking thing about this solution is that it does not depend at all on how prices are set, or how persistent is price stickiness. The exchange rate is equal to the

\footnotetext{
${ }^{4}$ We assume $\Gamma_{0}=1$.
} 
relative money supplies whether or not nominal goods prices are fixed in the currency of households or producers, and no matter how long it takes prices to adjust. Indeed, the equation holds whether or not there is any nominal price stickiness. The intuition for the result is that the marginal utility of nominal balances in the home and foreign countries are $\chi / M_{t}$ and $\chi / M_{t}^{*}$, respectively. The complete set of nominal assets ensures that the marginal utility of money, expressed in a common currency, is equalized. This relationship is expressed in Eq. (1.5). With complete markets, then, there can be no excess volatility.

\subsection{Extending the preference specification}

Is this conclusion sensitive to our particular preference specification? The fact that exchange rate volatility is independent of how prices are set is an artifact of our assumption that real balances enter the utility function logarithmically. For instance, we could allow a more general functional form for money in the utility function, such as $(1 /(1-\varepsilon))\left(M_{t} / P_{t}\right)^{1-\varepsilon}$. Going through the same steps leads us to the exchange rate solution

$$
S_{t}=\left(\frac{M_{t}}{M_{t}^{*}}\right)^{\varepsilon}\left(\frac{P_{t}^{*}}{P_{t}}\right)^{\varepsilon-1} \frac{\left(1-\mathrm{E}_{t} q_{t}\right)}{\left(1-\mathrm{E}_{t} q_{t}^{*}\right)}
$$

It is no longer true, in the case $\varepsilon \neq 1$, that the nominal interest rate is constant. Therefore, the exchange rate will, in general, depend on the response of home and foreign nominal interest rates. This precludes an analytic solution to (1.6). But we may linearize (1.6) in the neighborhood of a deterministic steady state. Define $x=$ $\ln X_{t}-\ln \bar{X}$. Then using the condition for uncovered interest rate parity, we may obtain the approximate solution

$$
s_{t}=\varepsilon\left(m_{t}-m_{t}^{*}\right)+(\varepsilon-1)\left(p_{t}^{*}-p_{t}\right)+\frac{1}{i} \mathrm{E}_{t}\left(s_{t+1}-s_{t}\right)
$$

where $i$ is the common steady state nominal interest rate in each country. Now we take the analogue of condition (1.4) to be that the log of the money supply is a random walk in each country. If there is full PCP price setting, where the law of one price holds for all goods, we would have $p_{t}=s_{t}+p_{t}^{*}$, and the solution for Eq. (1.7) is the same as (1.5), so the exchange rate is proportional to fundamentals, even in this extended model.

On the other hand, if there is complete LCP pricing, then the solution to Eq. (1.7) gives the exchange rate response

$$
s_{t}=\frac{(1+\varepsilon i)}{(1+i)}\left(m_{t}-m_{t}^{*}\right)
$$

For $\varepsilon>1$, the exchange rate can display volatility in excess of fundamentals, and volatility under LCP pricing exceeds that under PCP pricing. Note, however, that since $i$ is the nominal interest rate, it would take extremely large values of $\varepsilon$ to generate a very high exchange rate response to money shocks. Moreover, high exchange rate volatility can only be generated if the marginal utility of consumption 
is very volatile (from Eq. (1.1)). In this setting, a high value of $\varepsilon$ implies a high response of the marginal utility of aggregate consumption to monetary shocks. ${ }^{5}$

\section{Incomplete markets and local distribution}

Having established that a complete market setup cannot give an adequate description of exchange rate volatility, ${ }^{6}$ we now turn to a setting with limited financial markets. For the rest of the paper, we maintain the assumption that consumer prices are set (in advance) in local currency. But we allow for differences in the identity of the price setters of consumer goods. Domestic firms are all owned only by domestic residents, and foreign firms by foreign residents. But there are two types of firms in each country: producers and distributors. Each producer sells its product directly to residents of its own country without benefit of a distributor. But when marketing its product to the other country there are two possibilities. Home producers, for example, might choose to sell directly to foreign households or they might sell to a foreign-owned distributor. The foreign distributor then sells the home-produced product to foreign households.

If the home producer sells directly to foreign households, it sets prices in the foreign currency. However, if the home producer sells to foreign distributors, it sets a price in home currency. The distributor absorbs the exchange rate risk because it buys at prices set in the home currency, but it sets prices for foreign consumers in foreign currency. Distributors use no resources. Their only role is to purchase goods from producers priced in the producers' currencies, and then sell those goods to consumers at a price set in consumers' currencies.

In particular, our model deliberately eliminates any "expenditure switching” role for exchange rates, in order to highlight the role of the contribution of local-currency pricing to exchange rate volatility. Some studies (McCallum and Nelson, 2000; Obstfeld, 2001) have allowed for a difference between import prices and consumer prices as we do, but posit that the distributors have a wide scope for substituting between imports and domestically produced alternatives when the exchange rate changes. The distributor in those models combines imports and home products to make the final consumer good, and can vary the proportion of the intermediate products in the final good. In essence, we have made the extreme assumption that the distributor has zero elasticity of substitution between imports and home products.

Producers manufacture output from labor, using a linear technology. Each production firm is a monopolist, and sets prices in advance to maximize expected discounted profits. Sales are demand determined. We assume that distributors sign binding contracts ex ante to distribute however much of the good is demanded. After the state of the world is realized, distributors might find themselves either making

\footnotetext{
${ }^{5}$ Note that in a one-period economy, which can be interpreted as the case $i \rightarrow \infty$, the elasticity of the exchange rate fundamentals is equal to $\varepsilon$, which in principle may be very large. But again, this implies a high volatility of the marginal utility of consumption.

${ }^{6}$ For the rest of the paper, we return to the original preference specification of Section 1.
} 
pure profit or pure loss on each unit that they sell. However, they cannot exit the market if they are making a loss. We also assume that there is free entry ex ante into the distribution market. That means that prices by distributors are set so that expected discounted profits from distribution are zero in equilibrium. ${ }^{7}$

Producers. First let us look at the situation of the home producing firm. A home producer $j$ sets price $P_{\mathrm{h} t}(j)$ in home currency for sales to the home market. If the home producer distributes directly to a foreign household, she sets a price $P_{\mathrm{h} t}^{\mathrm{P}^{*}}(j)$ in the foreign currency. But if she sells to a distributor, she sets a price $Q_{\mathrm{h} t}(j)$ in the home currency. The foreign distributor buys the good at $Q_{\mathrm{h} t}(j)$ per unit, and sells to households at a price $P_{\mathrm{h} t}^{\mathrm{D}^{*}}(j)$ set in foreign currency. ${ }^{8}$ The price index of home goods for foreign consumers $P_{\mathrm{h} t}^{*}$ is given by $P_{\mathrm{h} t}^{*}=\left(\theta\left(P_{\mathrm{h} t}^{P^{*}}\right)^{1-\lambda}+(1-\theta)\left(P_{\mathrm{h} t}^{D^{*}}\right)^{1-\lambda}\right)^{1 /(1-\lambda)}$ where $\theta$ is the fraction of home firms that sell directly to households in the foreign country.

Revenues of home producer $j$ from sales of home goods are given by

$$
n P_{\mathrm{h} t}(j)\left(\frac{P_{\mathrm{h} t}(j)}{P_{\mathrm{h} t}}\right)^{-\lambda}\left(\frac{P_{\mathrm{h} t}}{P_{t}}\right)^{-\omega} C_{t},
$$

which represents the demand for product $j$ of the $n$ home households multiplied by the price of product $j$. If the producer markets directly to foreign households, revenue from foreign sales is

$$
(1-n) S_{t} P_{\mathrm{h} t}^{\mathrm{P}^{*}}(j)\left(\frac{P_{\mathrm{h} t}^{\mathrm{P}^{*}}(j)}{P_{\mathrm{h} t}^{*}}\right)^{-\lambda}\left(\frac{P_{\mathrm{h} t}^{*}}{P_{t}^{*}}\right)^{-\omega} C_{t}^{*}
$$

in domestic currency. This comes from taking the demand for product $j$ of the $1-n$ foreign households, multiplying by the foreign price of product $j$ and by the exchange rate to express in domestic currency.

If the home producer decides to engage a foreign distributor, however, revenues are given by

$$
(1-n) Q_{\mathrm{h} t}(j)\left(\frac{P_{\mathrm{h} t}^{\mathrm{D}^{*}}(j)}{P_{\mathrm{h} t}^{*}}\right)^{-\lambda}\left(\frac{P_{\mathrm{h} t}^{*}}{P_{t}^{*}}\right)^{-\omega} C_{t}^{*} .
$$

This represents the demand for product $j$ by all $(1-n)$ foreign households, multiplied by the domestic currency price that is charged to foreign distributors.

Distributors. A home country firm that engages in the distribution of foreign good $j$ has revenue

$$
n P_{\mathrm{f} t}^{\mathrm{D}}(j)\left(\frac{P_{\mathrm{f} t}}{P_{t}}\right)^{-\omega}\left(\frac{P_{\mathrm{f} t}^{\mathrm{D}}(j)}{P_{\mathrm{f} t}}\right)^{-\lambda} C,
$$

\footnotetext{
${ }^{7}$ This is essentially the set-up we used in Devereux et al. (1999). In that paper, we assumed that all exported goods were sold by distributors. In a complete markets setting, we showed that this implied an equivalent allocation to the situation where exports are sold directly to the foreign consumer. By contrast, here we allow some exports to go through distributors, and some to be sold directly by producers to households, and of course, we do not assume that markets are complete.

${ }^{8}$ Under complete markets, we would have $P_{\mathrm{h} t}^{\mathrm{P}^{*}}(j)=P_{\mathrm{h} t}^{\mathrm{D}^{*}}(j)$ (see Devereux et al., 1999).
} 
which represents the demand for good $j$ by all $n$ home residents multiplied by the price of good $j$. The costs incurred by the home country distributor are

$$
n S_{t} Q_{\mathrm{f} t}^{*}(j)\left(\frac{P_{\mathrm{f} t}^{\mathrm{D}}(j)}{P_{\mathrm{f} t}}\right)^{-\lambda}\left(\frac{P_{\mathrm{f} t}}{P_{t}}\right)^{-\omega} C_{t},
$$

since the foreign producer $j$ sells her good denominated in foreign currency at the price $Q_{\mathrm{f} t}^{*}(j)$.

Profits. Now imposing a symmetric equilibrium, so that producers in any subcategory always set the same prices, we can calculate the total profits received by the $n$ home country firms, of whom $\theta$ directly market to foreign households, and $1-\theta$ sell to foreign country distributors, as well as the $(1-n)\left(1-\theta^{*}\right)$ home firms who engage in distributing foreign products. Total profit income received by home country consumers may then be written as

$$
\begin{aligned}
& n^{2} P_{\mathrm{h} t}\left(\frac{P_{\mathrm{h} t}}{P_{t}}\right)^{-\omega} C_{t}+\theta(1-n) n S_{t} P_{\mathrm{h} t}^{\mathrm{P}^{*}}\left(\frac{P_{\mathrm{h} t}^{\mathrm{P}^{*}}}{P_{\mathrm{h} t}^{*}}\right)^{-\lambda}\left(\frac{P_{\mathrm{h} t}^{*}}{P_{t}^{*}}\right)^{-\omega} C_{t}^{*} \\
& +(1-\theta)(1-n) n Q_{\mathrm{h} t}\left(\frac{P_{\mathrm{h} t}^{\mathrm{D}^{*}}}{P_{\mathrm{h} t}^{*}}\right)^{-\lambda}\left(\frac{P_{\mathrm{h} t}^{*}}{P_{t}^{*}}\right)^{-\omega} C_{t}^{*} \\
& +\left(1-\theta^{*}\right) n(1-n)\left(P_{\mathrm{f} t}^{\mathrm{D}}-S_{t} Q_{\mathrm{f} t}^{*}\right)\left(\frac{P_{\mathrm{f} t}^{\mathrm{D}}}{P_{\mathrm{f} t}}\right)^{-\lambda}\left(\frac{P_{\mathrm{f} t}}{P_{t}}\right)^{-\omega} C_{t}-n W_{t} L_{t} .
\end{aligned}
$$

The first expression represents revenue from the home market. The second and third expressions represent revenue from the foreign market for the direct marketers and the firms that use a foreign distribution network, respectively. The fourth expression represents profits of home distributors, and finally the fifth expression measures total wage costs.

Foreign firms. Analogously, foreign producer $k$ sets the price $P_{\mathrm{f} t}^{*}(k)$ for sale to foreign residents. A fraction $\theta^{*}$ of foreign firms directly sell their product to home households at a home-currency price of $P_{\mathrm{f} t}^{\mathrm{P}}(k)$, while the remaining $1-\theta^{*}$ sell their product to home-based distributors at a price of $Q_{\mathrm{f} t}^{*}(k)$ in foreign currency. The home distributors sell those goods to home consumers at the price $P_{\mathrm{f} t}^{\mathrm{D}}(k)$. We have $P_{\mathrm{f} t}=\left(\theta^{*}\left(P_{\mathrm{f} t}^{\mathrm{P}}\right)^{1-\lambda}+\left(1-\theta^{*}\right)\left(P_{\mathrm{f} t}^{\mathrm{D}}\right)^{1-\lambda}\right)^{1 /(1-\lambda)}$. Foreign revenues may be evaluated in the same way as before, and total profits to foreign households are described by an equation analogous to (2.1).

Prices are set by home and foreign producing firms and distributors to maximize expected discounted profits. The full equilibrium of the dynamic model with incomplete markets requires a set of assumptions about the types of financial assets that households can trade between countries. But before we analyze the nature of international financial markets, it is instructive to explain how the structure of commodity distribution alone helps to generate high exchange rate volatility in an environment of local currency goods pricing. We do this by examining the special case of a one-period horizon. 


\subsection{Static model}

In a one-period version of the economy, there is no international asset trade of any kind, since bond trade can only take place over time. We may define an equilibrium as follows. ${ }^{9}$ Expression (2.2) and (2.3) describe money market clearing and the labor supply curve for the home country:

$$
\begin{aligned}
& M_{t}=\chi P_{t} C_{t}^{\rho}, \\
& W_{t}=\eta P_{t} C_{t}^{\rho} L_{t}^{\psi} .
\end{aligned}
$$

The budget constraint facing a typical home household is

$$
P_{t} C_{t}+M_{t}=W_{t} L_{t}+\Pi_{t}+T_{t}
$$

Here, $\Pi_{t}$ are profits from domestic producers and distributors as defined in (2.1) and $T_{t}$ is the transfer from the central bank. The home country goods market clearing condition is

$$
\begin{aligned}
L_{t}= & n\left(\frac{P_{\mathrm{h} t}}{P_{t}}\right)^{-\omega} C_{t}+(1-n) \theta\left(\frac{P_{\mathrm{h} t}^{\mathrm{P}^{*}}}{P_{\mathrm{h} t}^{*}}\right)^{-\lambda}\left(\frac{P_{\mathrm{h} t}^{*}}{P_{t}^{*}}\right)^{-\omega} C_{t}^{*} \\
& +(1-n)(1-\theta)\left(\frac{P_{\mathrm{h} t}^{\mathrm{D}^{*}}}{P_{\mathrm{h} t}^{*}}\right)^{-\lambda}\left(\frac{P_{\mathrm{h} t}^{*}}{P_{t}^{*}}\right)^{-\omega} C_{t}^{*}
\end{aligned}
$$

The left-hand side of this equation represents total home country output. The righthand side is demand for home country goods from home households, from the foreign households who buy directly from the home firms, and by foreign households who buy from foreign distributors.

Conditional on pre-set prices, a static equilibrium may be defined by Eqs. (2.2) and (2.3), and their counterparts for the foreign economy, the home country budget constraint (2.4) (recognizing the money market equilibrium condition $M_{t}=T_{t}$ ), and the goods market clearing condition (2.5) with its counterpart for the foreign economy. This gives a set of seven equations that gives implicit solutions for the seven variables $C_{t}, C_{t}^{*}, W_{t}, W_{t}^{*}, L_{t}, L_{t}^{*}$, and $S_{t}$. Combining (2.4) with the profit

\footnotetext{
${ }^{9}$ Technically, we obtain a one-period outcome by setting $\beta=0$ in the previous model (without the risksharing conditions).
} 
expression (2.1) gives the equation:

$$
\begin{aligned}
P_{t} C_{t}(1-n)\left(\frac{P_{\mathrm{h} t}}{P_{t}}\right)^{1-\omega}= & \theta(1-n) S_{t}\left(\frac{P_{\mathrm{h} t}^{\mathrm{P}^{*}}}{P_{\mathrm{h} t}^{*}}\right)^{1-\lambda}\left(\frac{P_{\mathrm{h} t}^{*}}{P_{t}^{*}}\right)^{1-\omega} P_{t}^{*} C_{t}^{*} \\
& +(1-\theta)(1-n) \frac{Q_{\mathrm{h} t}}{P_{\mathrm{h} t}^{\mathrm{D}^{*}}}\left(\frac{P_{\mathrm{h} t}^{\mathrm{D}^{*}}}{P_{\mathrm{h} t}^{*}}\right)^{1-\lambda}\left(\frac{P_{\mathrm{h} t}^{*}}{P_{t}^{*}}\right)^{1-\omega} P_{t}^{*} C_{t}^{*} \\
& +\left(1-\theta^{*}\right)(1-n)\left(1-\frac{S_{t} Q_{\mathrm{f} t}^{*}}{P_{\mathrm{f} t}^{\mathrm{D}}}\right)\left(\frac{P_{\mathrm{f} t}^{\mathrm{D}}}{P_{\mathrm{f} t}}\right)^{1-\lambda}\left(\frac{P_{\mathrm{f} t}}{P_{t}}\right)^{1-\omega} P_{t} C_{t} .
\end{aligned}
$$

In combination with (2.2) and its counterpart for the foreign economy, Eq. (2.6) determines home and foreign consumption, and the nominal exchange rate. Eq. (2.6) is simply the balance of payments equilibrium in the one-period world economy (to see this, note that in the special case when $\theta=\theta^{*}=1, \omega=1$, and prices set by direct marketers and distributors are identical, the condition just says that the nominal value of home spending should equal the nominal value of foreign spending; i.e. $\left.P_{t} C_{t}=S_{t} P_{t}^{*} C_{t}^{*}\right)$.

Notice that the exchange rate plays two roles on the right-hand side of (2.6). A depreciation will increase home country revenue by increasing the earnings of domestic firms who sell their products directly to foreign households and pre-set prices in the foreign currency. On the other hand, there is a negative wealth effect of exchange rate depreciation arising from the reduced profits of home country distribution firms, who have to purchase foreign goods at a higher domestic cost. It is the conflict between these two wealth impacts of exchange rates that is critical to the results below.

In general, the response of the exchange rate to monetary shocks will depend on the levels of pre-set home and foreign prices. However, we can again determine the degree of exchange rate volatility by examining the properties of the model in the neighborhood of a deterministic equilibrium. In a deterministic economy with $S=1$, it is easy to see in this case that $P_{\mathrm{h} t}^{\mathrm{P}^{*}}=P_{\mathrm{h} t}^{\mathrm{D}^{*}}=P_{\mathrm{h} t}^{*}, P_{\mathrm{f} t}^{\mathrm{P}}=P_{\mathrm{f} t}^{\mathrm{D}}=P_{\mathrm{f} t}, Q_{\mathrm{h} t} / P_{\mathrm{h} t}^{*}=$ $Q_{\mathrm{f} t}^{*} / P_{\mathrm{f} t}=1$. Then taking a log linear approximation of Eq. (2.2) (and its counterpart for the foreign country) and (2.6), we find that

$$
s_{t}=\frac{1}{\rho\left(\theta+\theta^{*}-1\right)}\left(m_{t}-m_{t}^{*}\right) .
$$

If all goods were directly marketed to households (i.e. $\theta=\theta^{*}=1$ ), exchange rates would be more stable in this setting than under complete markets. The response of the exchange to changes in the relative money supplies is $1 / \rho$. A reasonable assumption is that $\rho>1$, so the exchange rate elasticity is less than unity (as it would be under complete markets.) This is precisely the result in Engel (2001) under balanced trade.

But we have argued that some goods are likely to be priced in the producers' currencies and sold to distributors. In fact, it seems plausible that $\theta+\theta^{*}$ may be 
close to one. For example, when a large country sells to a small country, only a small fraction of firms might directly market their products, so $\theta$ will be small. But many of the small country exporters will directly market their goods in the large country, so $\theta^{*}$ would be large. It might be that the fraction of goods that are marketed are close to the relative size of the country, so $\theta$ may be close to $1-n$, and $\theta^{*}$ may be close to $n$.

As $\theta+\theta^{*}$ approaches unity from above, the response of the exchange rate to monetary shocks approaches infinity. The intuition is easy to see. With local currency pricing, there is no 'expenditure switching' effect of exchange rate changes. The only effect that the exchange rate has on the economy comes through its effect on profits. A home depreciation raises the profits of the $\theta$ home producers that directly sell their products to foreign producers. But a home depreciation lowers the ex post profits of the $1-\theta^{*}$ distributors in the home country that sell foreign products. Under balanced trade, when $\theta$ approaches $1-\theta^{*}$, the two effects cancel out. So, with this sort of asymmetric marketing, we can arrive at a situation where nominal exchange rate changes have essentially no effect on the economy. There is no expenditure-switching effect because all prices are set in the consumers' currencies. And the wealth effects on profits are nil as the gains from one sector of the economy cancel with the losses from another sector.

Note that this economy may exhibit very high exchange rate volatility without any equivalent volatility in real magnitudes. From (2.2) and (2.5) it is easy to establish that consumption and employment are

$$
\begin{aligned}
& c_{t}=\frac{m_{t}}{\rho}, \\
& l_{t}=\frac{n m_{t}+(1-n) m_{t}^{*}}{\rho} .
\end{aligned}
$$

Thus, the volatility in the nominal (and real) exchange rate may be out of all proportion to volatility in the underlying economy.

\section{Dynamic model}

The results so far provide some analytical support for the 'disconnectedness' of the exchange rate from the economy. But the absence of inter-temporal dynamics represents an important drawback of the analysis. Exchange rate changes had little impact on the static economy because they did not affect relative goods prices, and through the combination of local currency pricing and domestic distributors, both the expenditure switching and wealth effects of exchange rate shocks were limited. But in a dynamic model, an exchange rate shock also affects interest rates, and through a combination of uncovered interest rate parity (UIRP; this will hold in a linear approximate dynamic version of our economy), and temporary deviations from PPP, monetary shocks drive a wedge between real interest rates facing the home and foreign household. This real interest rate effect allows the exchange rate to play a critical role that is not present in the static model. As we show, the real interest 
rate mechanism may be important enough to sharply limit the volatility of the exchange rate.

But the real interest rate linkage relies critically upon the validity of UIRP. As is now well known, UIRP does very poorly as an empirical prediction in exchange rate data. Moreover, the literature has been unsuccessful in attributing deviations from UIRP to a risk premium based on utility-maximizing behavior. In fact, the literature has explored a number of possible avenues for explaining the deviations from UIRP in terms of a risk premium. These include generalizations of preferences to allow departures from time additivity, or from the axioms of expected utility. Models have explored the role of heteroskedasticity of driving variables, time aggregation, frictions in goods markets and consumption externatilities. Several recent studies have attempted to model deviations from UIRP as a risk premium, but have concluded that there remain fundamental obstacles to this approach. These studies include Bekaert (1996), Bekaert et al. (1997), Backus et al. (2001), and Moore and Roche (2003). Engel (1996) surveys earlier literature.

In light of these developments, it is plausible to turn to small deviations from rational expectations to reconcile the evidence on deviations from UIRP. Evidence from surveys of traders in foreign exchange markets has suggested departures from conditional unbiasedness (see Frankel and Froot, 1987; Froot and Frankel, 1989). Jeanne and Rose (2002) develop a model of noise trading in foreign exchange markets, where the presence of noise traders introduces a time-varying liquidity premium in the excess returns on foreign currency investments (or a liquidity premium in UIRP). In this section, we extend our basic model of local currency pricing and international marketing to incorporate a noise-trader generated liquidity premium in foreign exchange rates. Using the framework of Jeanne and Rose, we show that, even in a dynamic model, the link between exchange rates and fundamentals is weakened dramatically. The combination of local currency pricing, asymmetric marketing, and the presence of noise-trading liquidity premiums in foreign exchange markets generate the fundamental features of 'disconnection' between exchange rates and fundamentals.

Households. Households now trade in domestic and international bonds. Since incomplete markets are critical, our assumption is that households can trade in noncontingent nominal bonds only. Household bond trading is defined in a special way however. First, we assume that households can directly trade only in domestic currency denominated nominal bonds. All home country trading in foreign currency bonds is carried out by 'foreign exchange dealers' the activities of which will be described more fully below. Foreign exchange dealers give households a net payment of $\Pi_{t}^{\mathrm{f}}$ per period, denominated in domestic currency, which the households take as given. In fact, this may be positive or negative, as the households may be required to pay in to the foreign exchange fund in some periods. Since foreign exchange dealers act in household's interests, this represents a delegation by households of all foreign exchange transactions to specialized dealers.

The budget constraint of the typical home household is then written as

$$
P_{t} C_{t}+\mathrm{d}_{t} B_{t+1}+M_{t}=W_{t} L_{t}+\Pi_{t}+\Pi_{t}^{\mathrm{f}}+M_{t-1}+T_{t}+B_{t}
$$


All variables are defined as before. $B_{t}$ is the number of domestic currency denominated bonds held by the home household, and $d_{t}$ is defined as the price of a bond. ${ }^{10} \Pi_{t}$ represents profit income from production and distribution firms, as defined in (2.1). $\Pi_{t}^{\mathrm{f}}$ is the payment made by foreign exchange dealers at time $t$.

Conditions describing optimal behavior for the home household include (1.2), (1.3), and

$$
d_{t}=\mathrm{E}_{t} \beta \frac{P_{t} C_{t}^{\rho}}{P_{t+1} C_{t+1}^{\rho}},
$$

which is the Euler equation for optimal choice of domestic currency bonds.

Foreign country residents have identical preferences, but trade directly in foreign currency bonds. Given the institutional setup for foreign exchange trading that is described below, it is irrelevant whether foreign residents trade directly in foreign currency denominated bonds, or have this done by specialized foreign exchange traders. In addition, we assume that foreign residents do not trade in domestic currency denominated bonds. Accordingly, we may write the foreign residents budget constraint as

$$
P_{t}^{*} C_{t}^{*}+d_{t}^{*} B_{\mathrm{f} t+1}^{*}+M_{t}^{*}=W_{t}^{*} L_{t}^{*}+\Pi_{t}^{*}+M_{t-1}^{*}+T_{t}^{*}+B_{\mathrm{f} t}^{*},
$$

where $d_{t}^{*}$ is the price of a unit of foreign currency delivered in period $t+1$. Optimal behavior for foreign residents involves the analogous conditions to (1.2) and (1.3), as well as the condition describing the optimal choice of bond holdings:

$$
d_{t}^{*}=\mathrm{E}_{t} \beta \frac{P_{t}^{*} C_{t}^{* \rho}}{P_{t+1}^{*} C_{t+1}^{* \rho} .}
$$

Foreign exchange dealers. In the home country, foreign exchange dealers buy or sell foreign currency denominated bonds to maximize the discounted expected returns of cash flow, evaluated at the home household's discount rate. Expected returns are

$$
\mathrm{E}_{t}^{n}\left(q_{t} S_{t+1} B_{\mathrm{h} t+1}^{*}-d_{t}^{*} S_{t} B_{\mathrm{h} t+1}^{*}\right)
$$

where $\mathrm{E}_{t}^{n}$ represents profit expectations taken by the foreign exchange dealers, and $q_{t}$ represents the state contingent value of domestic currency delivered in period $t+1$ $\left(q_{t}=\beta\left(P_{t} C_{t}^{\rho} / P_{t+1} C_{t+1}^{\rho}\right)\right)$. Home country residents receive an amount $S_{t} B_{\mathrm{h} t}^{*}$ from foreign exchange dealers at time $t$, and make new payments of $d_{t}^{*} S_{t} B_{\mathrm{h} t+1}^{*}$ to the dealers. Thus, the net amount received by home residents is $\Pi_{t}^{\mathrm{f}}=S_{t} B_{\mathrm{h} t}^{*}-d_{t}^{*} S_{t} B_{\mathrm{h} t+1}^{*}$. This is the current return on the foreign exchange fund for home residents.

We assume that foreign exchange dealers exhibit bias in their conditional forecasts of the future exchange rate. Thus, they can be thought of as 'noise traders'. Following closely the work of Jeanne and Rose (2002), ${ }^{11}$ we make the following assumption about noise trader's subjective distribution over the log of the

\footnotetext{
${ }^{10}$ In equilibrium there will be zero net trade in these bonds, but it is convenient to define the equilibrium price $d_{t}$.

${ }^{11}$ Jeanne and Rose (2002) model the entry and exit of noise traders, which we neglect. However, the macroeconomic model of Jeanne and Rose is not fully developed. They use an ad hoc monetarist model.
} 
exchange rate. $^{12}$

$$
\begin{aligned}
& \mathrm{E}_{t}^{n} s_{t+1}=\mathrm{E}_{t} s_{t+1}+v_{t}, \\
& \operatorname{Var}_{t}^{n}\left(s_{t+1}\right)=\operatorname{Var}_{t}\left(s_{t+1}\right) .
\end{aligned}
$$

Here, we assume that $v_{t}$ is i.i.d. and satisfies; $\mathrm{E}_{t-1}\left(v_{t}\right)=0$. The notation $\mathrm{E}_{t-1}^{n}\left(x_{t}\right)$ refers to the conditionally biased expectations of noise traders. The period $t+1$ exchange rate expected by noise traders based on period $t$ information differs from the true conditional expectation by a random error. But noise traders correctly forecast the conditional variance of the exchange rate. Finally, we assume that the conditional variance of $v_{t}$ is proportional to the conditional variance of the exchange rate itself. Thus

$$
\operatorname{Var}_{t-1}\left(v_{t}\right)=\kappa^{2} \operatorname{Var}_{t-1}\left(s_{t}\right), \quad 0 \leqslant \kappa<1 .
$$

The logic behind condition (3.6) is that the bias in noise trader expectations must be related to the volatility of the exchange rate itself, since otherwise, noise traders might anticipate that the future exchange rate was volatile, even in a fixed exchange rate regime. $^{13}$

Finally, we assume that foreign exchange dealers make accurate expectations of the households state contingent discount factor $q_{t}{ }^{14}$

Assuming that there is no entry cost into the foreign exchange dealing market, but that each new (home country) foreign exchange dealer continues to exhibit biased expectations, we have expected returns driven to zero, so that

$$
d_{t}^{*}=\mathrm{E}_{t}^{n} \frac{q_{t} S_{t+1}}{S_{t}} .
$$

Firms. The expressions for revenue of home and foreign firms are the same as before, and firms use the same pricing rules as before. Now, however, a money shock may have long-lived effects through its impact on the current account (as in Obstfeld and Rogoff, 1995).

Model solution. The Appendix A describes the complete solution of the model. Here, we take a heuristic approach. Again, we characterize the properties of exchange rates by taking a linear approximation around an initial non-stochastic, symmetric steady state. Thus, we let lower case letters represent log deviations from an initial steady state, so that $x_{t}=\ln \left(X_{t}\right)-\ln (\bar{X})$. In the initial steady state consumption, net foreign assets, prices and the exchange rate are all constant. Again,

\footnotetext{
${ }^{12}$ Since our approximate model below is written in terms of $\log$ deviations from the steady state, we must make distributional assumptions with respect to the logs of the exchange rate.

${ }^{13}$ It may seem strange that the conditional variance of $v_{t}$ is proportional to the conditional variance of $s_{t}$ rather than of $s_{t+1}$. But in fact, as we show below, the conditional variance of the exchange rate is constant over time.

${ }^{14}$ We could rationalize this under the supposition that there existed a full set of state contingent home currency bonds, traded only within the home country, so that the bond prices would reveal the state discount factor.
} 
we assume that money shocks are given by

$$
m_{t}=m_{t-1}+u_{t}, \quad m_{t}^{*}=m_{t-1}^{*}+u_{t}^{*},
$$

where $\mathrm{E}_{t-1} u_{t}=\mathrm{E}_{t-1} u_{t}^{*}=0$.

To begin with, we may establish that, in a linear approximation, firms will set prices to equal anticipated marginal costs ${ }^{15}$

$$
p_{\mathrm{h} t}=\mathrm{E}_{t-1} w_{t}, \quad p_{\mathrm{h} t}^{*}=\mathrm{E}_{t-1}\left(w_{t}-s_{t}\right) .
$$

A similar result holds for the foreign prices. Together, this implies that the price index for home and foreign countries is

$$
\begin{aligned}
& p_{t}=n \mathrm{E}_{t-1} w_{t}+(1-n) \mathrm{E}_{t-1}\left(w_{t}^{*}+s_{t}\right), \\
& p_{t}^{*}=n \mathrm{E}_{t-1}\left(w_{t}-s_{t}\right)+(1-n) \mathrm{E}_{t-1} w_{t}^{*} .
\end{aligned}
$$

Eqs. (3.8) and (3.9) together imply that in an expected sense, PPP holds. Not surprisingly, with one-period ahead pricing and without non-traded goods, our model does not address the determinants of persistence in the real exchange rate.

Interest rate parity. We may derive the interest rate parity relationships implied by this model by taking a linear approximation of (3.3) and (3.7), taking into account the assumption on foreign exchange dealer's expectations (3.4). This gives

$$
\begin{aligned}
& \rho \mathrm{E}_{t}\left(c_{t+1}-c_{t}\right)+\mathrm{E}_{t}\left(p_{t+1}-p_{t}\right) \\
& \quad=\rho \mathrm{E}_{t}\left(c_{t+1}^{*}-c_{t}^{*}\right)+\mathrm{E}_{t}\left(p_{t+1}^{*}-p_{t}^{*}\right)+\mathrm{E}_{t} s_{t+1}-s_{t}+v_{t} .
\end{aligned}
$$

The expression on the left-hand side of this equation has the interpretation as the domestic nominal interest rate. The first two expressions on the right-hand side represent the foreign nominal interest rate. Eq. (3.10) then says that the presence of conditionally biased expectations introduces a stochastic deviation from uncovered interest rate parity. The source of this deviation is precisely the bias in expectations of the future exchange rate. It is important to distinguish between this deviation from UIRP and deviations due to conventional risk premium terms, which would arise from risk aversion and Jensen's inequality terms in the true non-linear solution (as opposed to the linear approximation). These conventional risk-premium terms tend to be both very small and have little variability (see Engel, 1996.) By contrast, the liquidity premium arising from noise-traders is on average zero, but displays volatility that is proportional to the exchange rate itself.

Eq. (3.10) also implies that while UIRP may fail due to expectational shocks on the part of noise traders, it holds in expected value. Conditional on period $t-1$ information, nominal interest rate differentials reflect expected changes in exchange rates.

Solving for expected values. Now using (3.8), (3.9), and a linear approximation of (1.3) and (2.5), (and the equivalent for the foreign country), and taking expectations dated $t-1$, we get

\footnotetext{
${ }^{15}$ Although the foreign currency price of imports from the home country depends on the price set both by home firms selling directly to the foreign market, and foreign retailers, it can easily be shown that they both set the same price, up to a linear approximation.
} 


$$
\mathrm{E}_{t-1}\left(w_{t}-w_{t}^{*}-s_{t}\right)=\frac{\rho}{(1+\psi \omega)} \mathrm{E}_{t-1}\left(c_{t}-c_{t}^{*}\right) .
$$

Take a linear approximation of the balance of payment constraint (3.1) (after imposing home money market equilibrium $M_{t}=M_{t-1}+T_{t}$, and the equilibrium relationship for profits of the producers and foreign exchange dealers), using the fact that (as will hold in equilibrium) in an expected sense, any initial change in net foreign assets is persistent, and then using the pricing equations above, we get

$$
\mathrm{E}_{t-1}\left(c_{t}-c_{t}^{*}\right)=(1-\omega) \mathrm{E}_{t-1}\left(w_{t}-w_{t}^{*}-s_{t}\right)+(1-\beta) \frac{\mathrm{d} B_{\mathrm{h} t}^{*}}{(1-n) P C} .
$$

This says that relative home consumption is increasing in the change in the initial home country expected net foreign asset position, and decreasing in the expected terms of trade (as long as $\omega>1$ ). Eqs. (3.11) and (3.12) give a relationship between the expected consumption differential and the initial net foreign assets:

$$
\mathrm{E}_{t-1}\left(c_{t}-c_{t}^{*}\right)=\frac{1-\beta}{\sigma} \frac{\mathrm{d} B_{\mathrm{h} t}^{*}}{(1-n) P C}
$$

where $\sigma \equiv(1-((1-\omega) \rho /(1+\psi \omega)))$. An increase in the home country net foreign assets leads to an anticipated rise in home consumption, relative to foreign consumption. ${ }^{16}$ Net foreign assets represent the only persistent state variable in the model.

Now take a linear approximation of the home and foreign money market conditions, using condition (3.13), and take expectations. This gives us the solution for the expected exchange rate

$$
\mathrm{E}_{t-1} s_{t}=\mathrm{E}_{t-1}\left(m_{t}-m_{t}^{*}\right)-\rho \mathrm{E}_{t-1}\left(c_{t}-c_{t}^{*}\right) .
$$

In an expected sense, the exchange rate is consistent with the standard monetary model.

Effect of money shocks on exchange rates. Now let $\hat{x} \equiv x-\mathrm{E}_{t-1} x$ represent the deviation of a variable from its expected value, where the expectation is dated $t-1$. Thus, $\mathrm{E}_{t} \hat{x}_{t+1}=\mathrm{E}_{t} x_{t+1}-\mathrm{E}_{t-1} x_{t+1}$, etc. Now, from the linear approximation of the balance of payments constraint, we can establish that

$$
\hat{c}_{t}-\hat{c}_{t}^{*}+\frac{\beta \mathrm{d} \hat{B}_{\mathrm{h} t+1}^{*}}{(1-n) P C}=\left[\theta-\left(1-\theta^{*}\right)\right] \hat{s}_{t} .
$$

The right-hand side of (3.15) represents the relative wealth impact of unanticipated shocks to the exchange rate. As in the previous section, if $\theta+\theta^{*}>1$, an unanticipated depreciation raises relative wealth of the home country. This relative wealth increase will then be spread between an increase in relative home consumption, and net foreign asset accumulation.

Using (3.13) (updated to period $t+1$ ) in Eq. (3.15) gives us a relationship between current relative consumption, expected period $t+1$ relative consumption, and the

\footnotetext{
${ }^{16}$ To avoid issues of 'immiserizing growth', we assume that $(1-\omega) \rho /(1+\psi \omega)<1$.
} 
unanticipated movement in the exchange rate:

$$
\hat{c}_{t}-\hat{c}_{t}^{*}+\frac{\sigma}{r} \mathrm{E}_{t}\left(\hat{c}_{t+1}-\hat{c}_{t+1}^{*}\right)=\left[\theta-\left(1-\theta^{*}\right)\right] \hat{s}_{t} .
$$

What is the relationship between current relative consumption and anticipated future relative consumption? Take the interest rate parity Eq. (3.10), and take expectations dated $t-1$. Since PPP is expected to hold at time $t+1$, and the current price level in both countries is predetermined, we may subtract the dated $t-1$ expected value of (3.10) from (3.10) itself to get

$$
\rho \mathrm{E}_{t}\left(\hat{c}_{t+1}-\hat{c}_{t+1}^{*}\right)=\rho\left(\hat{c}_{t}-\hat{c}_{t}^{*}\right)-\hat{s}_{t}+v_{t}
$$

Expected consumption growth in the home country decreases in response to an unanticipated exchange rate depreciation, since this generates an unanticipated real depreciation, therefore reducing the home country real interest rate. But a 'noise' shock, representing a shock to foreign exchange traders expectations of the future exchange rate, will raise the home country real interest rate. This leads to a rise in expected home country relative consumption growth.

Now putting together (3.16) and (3.17), we obtain a relationship between the unanticipated movement in the exchange rate and the unanticipated movement in relative consumption

$$
\hat{s}_{t}=\frac{(1+(\sigma / r))\left(\hat{c}_{t}-\hat{c}_{t}^{*}\right)+\frac{\sigma}{r \rho} v_{t}}{\left[(\sigma / r \rho)+\theta-\left(1-\theta^{*}\right)\right]} .
$$

Finally, from the linear approximation to the money market equilibrium, and using (3.14) and (3.17), we may establish that

$$
\left(\hat{c}_{t}-\hat{c}_{t}^{*}\right)=\frac{\left(\hat{m}_{t}-\hat{m}_{t}^{*}\right)}{\rho},
$$

so that the unanticipated movement in the exchange rate is

$$
\hat{s}_{t}=\frac{(1+(\sigma / r))\left(\hat{m}_{t}-\hat{m}_{t}^{*}\right)+(\sigma / r) v_{t}}{\left[(\sigma / r)+\rho\left(\theta-\left(1-\theta^{*}\right)\right)\right]} .
$$

Unlike the static model of the last section, there is still a determinate exchange rate when $\theta+\theta^{*}=1$. This is because, through the interest rate parity condition (3.17), the relationship between expected future consumption and current consumption is affected by the movement in the exchange rate. That is, the exchange rate determines the optimal response of the current account to a money shock.

Can the exchange rate display 'excess volatility' in this environment? Recalling assumption (3.6), we may evaluate the conditional variance of the exchange rate 
from

$$
\begin{aligned}
& \operatorname{Var}_{t-1}\left(\hat{s}_{t}\right)=\frac{(1+(\sigma / r))^{2} \operatorname{Var}_{t-1}\left(\hat{m}_{t}-\hat{m}_{t}^{*}\right)}{\Phi^{2}\left[1-[\kappa \sigma / r \Phi]^{2}\right]}, \\
& \Phi=\left[\frac{\sigma}{r}+\rho\left(\theta-\left(1-\theta^{*}\right)\right)\right] .
\end{aligned}
$$

Given that the volatility of the conditional bias in noise traders expectations is determined by exchange rate volatility, the conditional volatility in the exchange rate depends only on fundamentals; i.e. on the volatility in relative moneys. Moreover, from an examination of (3.20), we may establish the following proposition.

Proposition. As $\theta+\theta^{*} \rightarrow 1$ from above, and for $\kappa=1$, the conditional volatility of the exchange rate rises without bound.

Proof. From examination of (3.20).

Thus, the presence of local currency pricing, combined with asymmetric distribution and noise trading in foreign exchange markets, implies a degree of exchange rate volatility that may be far in excess of the underlying shocks.

The intuitive explanation of the proposition comes from combining elements of the previous section on the static environment and the additional presence of noise traders in this dynamic economy. As before, the presence of local currency pricing and domestic distributors tends to remove both the substitution and the wealth effects of exchange rate movements, at any point in time. But without noise traders, an unanticipated shock to the exchange rate will drive a wedge between the real interest rate in the home and foreign country. For instance, an exchange rate depreciation in the home country will reduce the relative real interest rate in the home country, and tilt the path of consumption so that home consumers will wish to consume more in the present, relative to the future. Then, from (3.13) and (3.16), the movement in the exchange rate is limited by the degree to which the current account must adjust to maintain an expected future level of consumption (governed by the parameter $\sigma$ ), even if $\theta+\theta^{*}$ is very close to unity.

In general, Eqs. (3.16) and (3.17) with the expectational noise omitted reveal why exchange rates will not be volatile under interest parity when there is local-currency pricing. Any depreciation of the home currency implies an increase in wealth, as the domestic currency value of foreign sales increases. This works to increase both current and future consumption, as Eq. (3.16) demonstrates. But a depreciation in the current period raises the real exchange rate today relative to the real exchange rate in the future. (This period's real exchange rate rises one-for-one with the nominal exchange rate when there is local currency pricing. The future real exchange rate is fixed by long-run PPP.) So by interest parity (3.17), a current depreciation must raise current consumption relative to expected future consumption (holding foreign consumption constant). Disconnect means that current consumption does not change much when the exchange rate changes. The interest parity condition then 
only allows large increases in the nominal exchange rate and disconnect to occur simultaneously when there are large drops in expected future consumption. But this contradicts the implications of the wealth effect of the depreciation, which must engender a rise in expected future consumption. We can conclude that interest parity precludes exchange rate volatility under local-currency pricing.

But when exchange rate forecasts are biased by noise trader errors, and the conditional volatility of these errors are proportional to the exchange rate, then exchange rate volatility is not limited by the response of the current account, because of the direct presence of noise trader shocks which also drive a wedge between home and foreign real interest rates. Holding the $v_{t}$ shock constant, we see from (3.19) that the response of the exchange rate is limited by the inter-temporal current account parameters. But this does not effectively limit the magnitude of nominal exchange rate volatility, because the (conditional) volatility of $v_{t}$ itself is proportional to exchange rate volatility.

Moreover, the critical implication of our model is that exchange rate volatility exceeds that of other relative prices and aggregate variables. To see this, we note the following. First, from the money market equilibrium conditions (1.2), and the analogous condition for the foreign economy, it may be established that the nominal interest rate in each country is constant. This implies that consumption in each country responds in the same way as Eq. (2.8). Second, given that nominal prices are predetermined in each economy, it is easy to show from the labor market clearing condition (2.5) (and its equivalent for the foreign country) that employment and output in each country responds identically to shocks to world consumption; (i.e. by $\left.n \hat{c}_{t}+(1-n) \hat{c}_{t}^{*}\right)$, as in Eq. (2.9). Therefore, again, consumption and output volatility is proportional to the volatility of the monetary 'fundamentals'.

The movement in the home country current account is given by

$$
\frac{\beta \mathrm{d} \hat{B}_{\mathrm{h} t+1}^{*}}{(1-n) P C}=\frac{\left[\theta-\left(1-\theta^{*}\right)\right]\left(1 / \rho\left(\hat{m}_{t}-\hat{m}_{t}^{*}\right)\left(1+\frac{\sigma}{r}\right)+(\sigma / r \rho) v_{t}\right)}{\left[(\sigma / r \rho)+\theta-\left(1-\theta^{*}\right)\right]}-\left(\hat{c}_{t}-\hat{c}_{t}^{*}\right) .
$$

As $\theta-\left(1-\theta^{*}\right) \rightarrow 1$ from above, the response of the current account to a money shock approaches the negative of the response of relative consumption. Moreover, any impact of the noise trader shock $v_{t}$ tends to be eliminated.

Finally, we may establish that as $\theta-\left(1-\theta^{*}\right) \rightarrow 1$ from above, the response of the home country real interest rate to money disturbances converges to

$$
-\frac{r}{\sigma}\left(\hat{m}_{t}-\hat{m}_{t}^{*}\right)(1-n)-\hat{m}_{t}
$$

We draw the conclusion that the path of all real variables in the economy is essentially independent of exchange rate variability. The combined presence of local currency pricing, asymmetric marketing, and 'noise-trader' conditionally biased expectations in foreign exchange markets generates the possibility for a degree of short-term exchange rate volatility that is completely out of proportion to all shocks impacting on the economy. Thus, as in the static example above, in the full dynamic 
Table 1

\begin{tabular}{|c|c|c|c|c|}
\hline${ }_{t-1} \sigma_{s}^{2}$ & ${ }_{t-1} \sigma_{s}^{2}(\mathrm{PCP})$ & $\rho(s, c)$ & $\rho(s, \tilde{r})$ & $\theta+\theta^{*}$ \\
\hline \multicolumn{5}{|l|}{$\kappa=0$} \\
\hline 1.74 & 0.72 & 0.71 & -0.68 & 2.0 \\
\hline 1.8 & 0.72 & 0.71 & -0.69 & 1.75 \\
\hline 1.9 & 0.72 & 0.71 & -0.70 & 1.50 \\
\hline 2.0 & 0.72 & 0.71 & -0.71 & 1.25 \\
\hline 2.1 & 0.72 & 0.71 & -0.72 & 1.0 \\
\hline \multicolumn{5}{|c|}{$\kappa=0.5$} \\
\hline 2.2 & 0.78 & 0.63 & -0.59 & 2.0 \\
\hline 2.3 & 0.78 & 0.63 & -0.60 & 1.75 \\
\hline 2.5 & 0.78 & 0.62 & -0.61 & 1.50 \\
\hline 2.6 & 0.78 & 0.62 & -0.61 & 1.25 \\
\hline 2.8 & 0.78 & 0.61 & -0.62 & 1.0 \\
\hline \multicolumn{5}{|c|}{$\kappa=0.9$} \\
\hline 5.3 & 1.0 & 0.40 & -0.37 & 2.0 \\
\hline 6.1 & 1.0 & 0.38 & -0.36 & 1.75 \\
\hline 7.2 & 1.0 & 0.36 & -0.35 & 1.50 \\
\hline 8.8 & 1.0 & 0.34 & -0.33 & 1.25 \\
\hline 11.0 & 1.0 & 0.31 & -0.31 & 1.0 \\
\hline $\begin{array}{l}\text { Para } \\
\omega=\end{array}$ & 4. $n-$ & $\left.-c_{t}\right)$ & & \\
\hline
\end{tabular}

economy we may observe the basic pattern of 'disconnect' between the exchange rate and the rest of the economy.

Table 1 reports some illustrative estimates of the effect of local currency pricing, asymmetric distribution networks, and noise trading for the volatility of the exchange rate. ${ }^{17}$ Here, it is assumed that the money shocks are uncorrelated across countries, and that each has variance unity. The parameter values used in the calculations are reported at the end of the table. For any value of $\kappa$, a fall in the value of $\theta+\theta^{*}$ increases exchange rate volatility. For comparison the table reports the volatility under producer currency pricing, where the volatility of the exchange rate is lower, and is unaffected by movements in $\theta+\theta^{*}$. For higher values of $\kappa$ under LCP, the impact of a fall in $\theta+\theta^{*}$ on exchange rate volatility becomes dramatic. The table also shows the correlations of the exchange rate with consumption and the home real interest rate. These correlations are relatively insensitive to changes in parameters of the model that produce a very high volatility of the exchange rate. Thus, as exchange rate volatility rises in our model, there is neither an increased

\footnotetext{
${ }^{17}$ Clearly we have not developed a model with which we would try to "match moments" as is done in many calibrated models that are solved numerically. For example, there is no persistence in our model in either price stickiness or expectational errors, so we cannot hope to match the persistence of exchange rates.
} 
volatility of other macroeconomic variables, nor a large change in the correlation between the exchange rate and these variables. The correlation between output and the exchange rate is not reported, because in the symmetric case of equal sized countries and an identical distribution of monetary shocks across countries, this is in fact zero (this can be inferred directly from 3.10 and 3.19).

\section{Conclusions}

This paper has made an attempt at developing a fully specified general equilibrium model of the exchange rate which accords with the conjecture of Krugman (1989) that exchange rate volatility is extreme because fluctuations in the exchange rate matter so little for the economy. We show that a combination of local currency pricing, heterogeneity in international price-setting and goods distribution, and expectational biases in international financial markets may combine to produce very high exchange rate volatility without any implications for the volatility of other macroeconomic aggregates.

We have developed testable hypotheses about the nature of exchange rate volatility and exchange rate disconnect. In particular, there ought to be a greater disconnect when the degree of local-currency pricing is high and the wealth effects of exchange rate changes are small. But ours is not a fully developed model that is capable of matching all of the empirical features of exchange rates. In particular, in order to explain not just real exchange rate volatility but also persistence, we might want to have more persistent price setting, and perhaps endogenous capital accumulation. We could pay more attention to the underlying incentives that exporting firms have to set up foreign distribution networks, and the pricing structure they use in conjunction with this. We have focused on the extreme case in which there is no expenditure-switching effect of exchange rate changes, but a more realistic model would allow for some substitution possibilities. With respect to the presence of expectational errors in financial markets, we could explore in more detail the microeconomic foundations of noise traders. We have merely clarified what type of deviation from UIRP is necessary to generate very high exchange rate volatility in face of local currency pricing and heterogeneous distribution of products. Nevertheless, our results suggest a number of key elements that may be part of the 'exchange rate disconnect' puzzle.

\section{Appendix A}

Here we derive the results that are obtained in Section 3 of the paper. The full model can be described by the following 18 equations. Given the definition of foreign exchange dealer profits, consumer price indices, and the conditional bias in expectations, these implicitly give a solution for the sequence; $C_{t}, C_{t}^{*}, W_{t}, W_{t}^{*}, S_{t}, B_{\mathrm{h} t}^{*}, d_{t}, d_{t}^{*}, L_{t}, L_{t}^{*}, P_{\mathrm{h} t}, P_{\mathrm{f} t}^{*}, P_{\mathrm{h} t}^{\mathrm{P}^{*}}, P_{\mathrm{f} t}^{\mathrm{P}}, P_{\mathrm{h} t}^{\mathrm{D}^{*}}, P_{\mathrm{f} t}^{\mathrm{D}}, Q_{\mathrm{h} t}, Q_{\mathrm{f} t}^{*}$. 


$$
\begin{aligned}
& P_{t} C_{t}+d_{t} B_{t+1}+M_{t}=W_{t} L_{t}+\Pi_{t}+\Pi_{t}^{\mathrm{f}}+M_{t-1}+T_{t}+B_{t}, \\
& L_{t}=\left(\frac{P_{\mathrm{h} t}}{P_{t}}\right)^{-\omega} n C_{t} \\
& +\left(\theta\left(\frac{P_{\mathrm{h} t}^{\mathrm{P}^{*}}}{P_{\mathrm{h} t}^{*}}\right)^{-\lambda}\left(\frac{P_{\mathrm{h} t}^{*}}{P_{t}^{*}}\right)^{-\omega}+(1-\theta)\left(\frac{P_{\mathrm{h} t}^{\mathrm{D}^{*}}}{P_{\mathrm{h} t}^{*}}\right)^{-\lambda}\left(\frac{P_{\mathrm{h} t}^{*}}{P_{t}^{*}}\right)^{-\omega}\right)(1-n) C_{t}^{*}, \\
& L_{t}^{*}=\left(\frac{P_{\mathrm{f} t}^{*}}{P_{t}^{*}}\right)^{-\omega}(1-n) C_{t}^{*} \\
& +\left(\theta^{*}\left(\frac{P_{\mathrm{f} t}^{\mathrm{P}}}{P_{\mathrm{f} t}}\right)^{-\lambda}\left(\frac{P_{\mathrm{f} t}}{P_{t}}\right)^{-\omega}+\left(1-\theta^{*}\right)\left(\frac{P_{\mathrm{f} t}^{\mathrm{D}}}{P_{\mathrm{f} t}}\right)^{-\lambda}\left(\frac{P_{\mathrm{f} t}}{P_{t}}\right)^{-\omega}\right) n C_{t}, \\
& W_{t}=\eta P_{t} C_{t}^{\rho} L_{t}^{\psi} \\
& W_{t}^{*}=\eta P_{t}^{*} C_{t}^{* \rho} L_{t}^{* \psi} \\
& d_{t}=\mathrm{E}_{t} \beta \frac{P_{t} C_{t}^{\rho}}{P_{t+1} C_{t+1}^{\rho}} \\
& d_{t}^{*}=\mathrm{E}_{t}^{n} \frac{q_{t} S_{t+1}}{S_{t}} \\
& d_{t}^{*}=\mathrm{E}_{t} \beta \frac{P_{t}^{*} C_{t}^{*} \rho}{P_{t+1}^{*} C_{t+1}^{* \rho}} \\
& P_{\mathrm{h} t}=\frac{\lambda}{\lambda-1} \frac{\mathrm{E}_{t-1}\left(W_{t} C_{t}^{1-\rho}\right)}{\mathrm{E}_{t-1}\left(C_{t}^{1-\rho}\right)} \\
& P_{\mathrm{f} t}^{*}=\frac{\lambda}{\lambda-1} \frac{\mathrm{E}_{t-1}\left(W_{t}^{*} C_{t}^{* 1-\rho}\right)}{\mathrm{E}_{t-1}\left(C_{t}^{* 1-\rho}\right)}, \\
& P_{\mathrm{h} t}^{P^{*}}=\frac{\lambda}{\lambda-1} \frac{\mathrm{E}_{t-1}\left(W_{t} C_{t}^{*} C_{t}^{-\rho}\right)}{\mathrm{E}_{t-1}\left(C_{t}^{*} C_{t}^{-\rho} S_{t}\right)}, \\
& P_{\mathrm{f} t}^{\mathrm{P}}=\frac{\lambda}{\lambda-1} \frac{\mathrm{E}_{t-1}\left(W_{t}^{*} C_{t} C_{t}^{*-\rho}\right)}{\mathrm{E}_{t-1}\left(C_{t} C_{t}^{*-\rho} / S_{t}\right)}, \\
& P_{\mathrm{h} t}^{\mathrm{D}^{*}}=Q_{\mathrm{h} t} \frac{\mathrm{E}_{t-1}\left(C_{t}^{* 1-\rho} / S_{t}\right)}{\mathrm{E}_{t-1}\left(C_{t}^{* 1-\rho}\right)}, \\
& P_{\mathrm{f} t}^{\mathrm{D}}=Q_{\mathrm{f} t}^{*} \frac{\mathrm{E}_{t-1}\left(S_{t} C_{t}^{1-\rho}\right)}{\mathrm{E}_{t-1}\left(C_{t}^{1-\rho}\right)},
\end{aligned}
$$




$$
\begin{aligned}
Q_{\mathrm{h} t} & =\frac{\lambda}{\lambda-1} \frac{\mathrm{E}_{t-1}\left(W_{t} C_{t}^{*} C_{t}^{-\rho}\right)}{\mathrm{E}_{t-1}\left(C_{t}^{*} C_{t}^{-\rho}\right)}, \\
Q_{\mathrm{f} t}^{*} & =\frac{\lambda}{\lambda-1} \frac{\mathrm{E}_{t-1}\left(W_{t}^{*} C_{t} C_{t}^{*-\rho}\right)}{\mathrm{E}_{t-1}\left(C_{t} C_{t}^{*-\rho}\right)}, \\
\frac{M_{t}}{P_{t}} & =\chi \frac{C_{t}^{\rho / \varepsilon}}{\left(1-d_{t}\right)^{1 / \varepsilon}}, \\
\frac{M_{t}^{*}}{P_{t}^{*}} & =\chi \frac{C_{t}^{*} \rho / \varepsilon}{\left(1-d_{t}^{*}\right)^{1 / \varepsilon}} .
\end{aligned}
$$

Eq. (A.1) is the home country balance of payments condition. Eqs. (A.2) and (A.3) represent the labor market clearing conditions for both countries. Eqs. (A.3) and (A.4) implicitly define labor supply conditions for each country. Eqs. (A.5)-(A.8) define the Euler equations for each country, as well as the expectations-biased form of the interest rate parity condition. Eqs. (A.9)-(A.16) represent the optimal pricing equations for firms in each country. ${ }^{18}$ Finally, Eqs. (A.17) and (A.18) represent the money market clearing conditions.

\section{Solution technique}

To solve this system, we take a linear approximation around an initial symmetric steady state, where net foreign assets are zero, all prices are equal, and the exchange rate is initially unity. Using lower case letters to designate a deviation from initial steady state, the linearized versions of the CPI price indices and Eqs. (A.9)-(A.16) are given by

$$
\begin{aligned}
& p_{t}=n p_{\mathrm{h} t}+(1-n) p_{\mathrm{f} t}=n p_{\mathrm{h} t}+(1-n)\left(\theta^{*} p_{\mathrm{f} t}^{\mathrm{P}}\right)+\left(1-\theta^{*}\right) p_{\mathrm{f} t}^{\mathrm{D}}, \\
& p_{t}^{*}=n p_{\mathrm{h} t}^{*}+(1-n) p_{\mathrm{f} t}^{*}=n\left(\theta p_{\mathrm{h} t}^{\mathrm{P}^{*}}+(1-\theta) p_{\mathrm{h} t}^{\mathrm{D}^{*}}\right)+(1-n) p_{\mathrm{f} t}^{*}, \\
& p_{\mathrm{h} t}=\mathrm{E}_{t-1} w_{t}, \quad p_{\mathrm{f} t}^{*}=\mathrm{E}_{t-1} w_{t}^{*}, \\
& p_{\mathrm{h} t}^{\mathrm{P}^{*}}=\mathrm{E}_{t-1}\left(w_{t}-s_{t}\right), \quad p_{\mathrm{h} t}^{\mathrm{D}^{*}}=\mathrm{E}_{t-1}\left(w_{t}-s_{t}\right), \\
& p_{\mathrm{f} t}^{\mathrm{P}}=\mathrm{E}_{t-1}\left(w_{t}^{*}+s_{t}\right), \quad p_{\mathrm{f} t}^{\mathrm{D}}=\mathrm{E}_{t-1}\left(w_{t}^{*}+s_{t}\right), \\
& q_{\mathrm{h} t}=\mathrm{E}_{t-1} w_{t}, \quad q_{\mathrm{f} t}^{*}=\mathrm{E}_{t-1} w_{t}^{*} .
\end{aligned}
$$

This implies that the CPI prices may be written as

$$
\begin{aligned}
& p_{t}=n \mathrm{E}_{t-1} w_{t}+(1-n) \mathrm{E}_{t-1}\left(w_{t}^{*}+s_{t}\right), \\
& p_{t}^{*}=n \mathrm{E}_{t-1}\left(w_{t}-s_{t}\right)+(1-n) \mathrm{E}_{t-1} w_{t}^{*} .
\end{aligned}
$$

\footnotetext{
${ }^{18}$ To derive the optimal pricing conditions, see Devereux et al. (1999).
} 
Linearizing the balance of payments condition (A.1), labor market clearing conditions (A.2) and (A.3), and the labor supply conditions (A.4) and (A.5), gives us (A.27).

$$
\begin{aligned}
& c_{t}+\frac{\beta \mathrm{d} B_{\mathrm{h} t+1}^{*}}{P C}=n c_{t}+n(1-\omega)\left(p_{\mathrm{h} t}-p_{t}\right) \\
& +(1-n) \theta\left[s_{t}+p_{\mathrm{h} t}^{*}-p_{t}+(1-\lambda)\left(p_{\mathrm{h} t}^{\mathrm{P} *}-p_{\mathrm{h} t}^{*}\right)-\omega\left(p_{\mathrm{h} t}^{*}-p_{t}^{*}\right)+c_{t}^{*}\right] \\
& +(1-n)(1-\theta)\left[q_{\mathrm{h} t}-p_{t}-\lambda\left(p_{\mathrm{h} t}^{\mathrm{D}^{*}}-p_{\mathrm{h} t}^{*}\right)-\omega\left(p_{\mathrm{h} t}^{*}-p_{t}^{*}\right)+c_{t}^{*}\right] \\
& +(1-n)\left(1-\theta^{*}\right)\left[(1-\lambda)\left(p_{\mathrm{f} t}^{\mathrm{D}}-p_{\mathrm{f} t}\right)+(1-\omega)\left(p_{\mathrm{f} t}-p_{t}\right)+c_{t}\right] \\
& -(1-n)\left(1-\theta^{*}\right)\left[s_{t}+q_{\mathrm{f} t}^{*}-p_{\mathrm{f} t}-\lambda\left(p_{\mathrm{f} t}^{\mathrm{D}}-p_{\mathrm{f} t}\right)\right. \\
& \left.+(1-\omega)\left(p_{\mathrm{f} t}-p_{t}\right)+c_{t}\right]+\frac{\mathrm{d} B_{\mathrm{h} t}^{*}}{P C}, \\
& l_{t}=n\left[-\omega\left(p_{\mathrm{h} t}-p_{t}\right)+c_{t}\right] \\
& +(1-n)\left[\theta\left(-\lambda\left(p_{\mathrm{h} t}^{\mathrm{P} *}-p_{\mathrm{h} t}^{*}\right)-\omega\left(p_{\mathrm{h} t}^{*}-p_{t}^{*}\right)\right)\right. \\
& \left.+(1-\theta)\left(-\lambda\left(p_{\mathrm{h} t}^{\mathrm{D}^{*}}-p_{\mathrm{h} t}^{*}\right)-\omega\left(p_{\mathrm{h} t}^{*}-p_{t}^{*}\right)\right)+c_{t}^{*}\right], \\
& l_{t}^{*}=(1-n)\left[-\omega\left(p_{\mathrm{f} t}^{*}-p_{t}^{*}\right)+c_{t}^{*}\right] \\
& +n\left[\theta^{*}\left(-\lambda\left(p_{\mathrm{f} t}^{\mathrm{P}}-p_{\mathrm{f} t}\right)-\omega\left(p_{\mathrm{f} t}-p_{t}\right)\right)\right. \\
& \left.+\left(1-\theta^{*}\right)\left(-\lambda\left(p_{\mathrm{f} t}^{\mathrm{D}}-p_{\mathrm{f} t}\right)-\omega\left(p_{\mathrm{f} t}-p_{t}\right)\right)+c_{t}\right], \\
& w_{t}=p_{t}+\rho c_{t}+\psi l_{t}, \\
& w_{t}^{*}=p_{t}^{*}+\rho c_{t}^{*}+\psi l_{t}^{*} \text {. }
\end{aligned}
$$

Finally, the linearization of the Euler equation, the interest rate parity equation, and the money market clearing conditions gives

$$
\begin{aligned}
& d_{t}=p_{t}+\rho c_{t}-\mathrm{E}_{t}\left(p_{t+1}+\rho c_{t+1}\right), \\
& d_{t}^{*}=p_{t}+\rho c_{t}-\mathrm{E}_{t}\left(p_{t+1}+\rho c_{t+1}\right)+\mathrm{E}_{t} s_{t+1}+v_{t}-s_{t}, \\
& d_{t}^{*}=p_{t}^{*}+\rho c_{t}^{*}-\mathrm{E}_{t}\left(p_{t+1}^{*}+\rho c_{t+1}^{*}\right), \\
& m_{t}-p_{t}=\frac{\rho}{\varepsilon} c_{t}+\frac{1}{\varepsilon r} d_{t}, \\
& m_{t}^{*}-p_{t}^{*}=\frac{\rho}{\varepsilon} c_{t}^{*}+\frac{1}{\varepsilon r} d_{t}^{*} .
\end{aligned}
$$

Now using (A.19)-(A.26), together with the assumption of i.i.d. shocks, in Eqs. (A.27)-(A.29), gives

$$
\begin{aligned}
& \mathrm{E}_{t-1}\left(c_{t}-c_{t}^{*}\right)=(1-\omega) \mathrm{E}_{t-1}\left(w_{t}-w_{t}^{*}-s_{t}\right)+(1-\beta) \frac{\mathrm{d} B_{\mathrm{h} t}^{*}}{(1-n) P C}, \\
& \mathrm{E}_{t-1}\left(l_{t}-l_{t}^{*}\right)=-\omega \mathrm{E}_{t-1}\left(w_{t}-w_{t}^{*}-s_{t}\right),
\end{aligned}
$$


where (A.37) represents (3.12) of the text. Now (A.30)-(A.31) and (A.35)-(A.36) give

$$
\begin{aligned}
& \mathrm{E}_{t-1}\left(w_{t}-w_{t}^{*}-s_{t}\right)=\rho \mathrm{E}_{t-1}\left(c_{t}-c_{t}^{*}\right)+\psi \mathrm{E}_{t-1}\left(l_{t}-l_{t}^{*}\right), \\
& \mathrm{E}_{t-1} s_{t}=\mathrm{E}_{t-1}\left(m_{t}-m_{t}^{*}\right)-\frac{\rho}{\varepsilon} \mathrm{E}_{t-1}\left(c_{t}-c_{t}^{*}\right) .
\end{aligned}
$$

So that

$$
\mathrm{E}_{t-1}\left(w_{t}-w_{t}^{*}-s_{t}\right)=\frac{\rho}{(1+\psi \omega)} \mathrm{E}_{t-1}\left(c_{t}-c_{t}^{*}\right),
$$

which is Eq. (3.11) of the text. From (A.37) and (A.41) we get (3.13) of the text.

To get (3.15) of the text, take the expectation of Eq. (A.27), and subtract from (A.27) itself. Then use (3.13) to derive (3.16). Eq. (3.17) is obtained by combining (A.33) and (A.34), imposing expected period $t+1$ PPP. Then, using (A.33)-(A.36), we may establish the relationship between money shocks and relative consumption used in deriving (3.19) of the text.

\section{References}

Bacchetta, P., van Wincoop, E., 2000. Does exchange rate stability increase trade and welfare? American Economic Review 90, 1093-1109.

Backus, D.K., Foresi, S., Telmer, C.I., 2001. Affine term-structure models and the forward premium anomaly. Journal of Finance 56, 279-304.

Baxter, M., Stockman, A., 1989. Business cycles and the exchange rate system. Journal of Monetary Economics 23, 377-400.

Bekaert, G., 1996. The time-variation of risk and return in foreign exchange markets: a general equilibrium perspective. Review of Financial Studies 9, 427-440.

Bekaert, G., Hodrick, R.J., Marshall, D.A., 1997. The implications of first-order risk aversion for asset market premiums. Journal of Monetary Economics 40, 3-39.

Betts, C., Devereux, M.B., 1996. The exchange rate in a model of pricing-to-market. European Economic Review 40, 1007-1021.

Betts, C., Devereux, M.B., 2000. Exchange rate dynamics in a model of pricing-to-market. Journal of International Economics 50, 215-244.

Chari, V.V., Kehoe, P.J., McGrattan, E.R., 2000. Can sticky price models generate volatile and persistent exchange rates? National Bureau of Economics Research, working paper no. 7869.

Devereux, M.B., Engel, C., 2000. Monetary policy in the open economy revisited: price-setting and exchange rate flexibility, National Bureau of Economic Research, working paper no. 7665.

Devereux, M.B., Engel, C., Tille, C., 1999. Exchange rate pass-through and the welfare effects of the euro, National Bureau of Economic Research, working paper no. 7382 (revised version forthcoming in International Economic Review).

Duarte, M., Stockman, A., 2001. Rational speculation and exchange rates, National Bureau of Economic Research, working paper no. 8362.

Engel, C., 1993. Real exchange rates and relative prices: an empirical investigation. Journal of Monetary Economics 32, 35-50.

Engel, C., 1996. The forward discount anomaly and the risk premium: a survey of recent evidence. Journal of Empirical Finance 3, 123-192.

Engel, C., 2001. Optimal exchange rate policy: the influence of price setting and asset markets. Journal of Money, Credit and Banking 33, 518-541.

Flood, R., Rose, A.K., 1995. Fixing exchange rates: a virtual quest for fundamentals. Journal of Monetary Economics 36, 3-37. 
Frankel, J.A., Froot, K.A., 1987. Using survey data to test standard propositions regarding exchange rate expectations. American Economic Review 77, 133-153.

Froot, K.A., Frankel, J.A., 1989. Forward discount bias: is it an exchange risk premium? Quarterly Journal of Economics 104, 139-161.

Jeanne, O., Rose, A.K., 2002. Noise trading and exchange rate regimes. Quarterly Journal of Economics $117,537-569$.

Krugman, P., 1989. Exchange Rate Instability. MIT Press, Cambridge, MA.

McCallum, B.T., Nelson, E., 2000. Monetary policy for an open economy: an alternative framework with optimizing agents and sticky prices. Oxford Review of Economic Policy 16, 74-91.

Moore, M.J., Roche, M.J., 2003. Less of a puzzle: a new look at the forward forex market. Journal of International Economics, forthcoming.

Obstfeld, M., 2001. International macroeconomics: beyond the Mundell-Fleming model. IMF Staff Papers 47, 1-39.

Obstfeld, M., Rogoff, K., 1995. Exchange rate dynamics redux. Journal of Political Economy 103, 624-660.

Obstfeld, M., Rogoff, K., 2000. The six major puzzles in international macroeconomics: is there a common cause? NBER Macroeconomics Annual 2000, 339-390.

Parsley, D.C., Wei, S.-J., 2001. Explaining the border effect: the role of exchange rate variability, shipping costs and geography. Journal of International Economics 55, 87-105. 